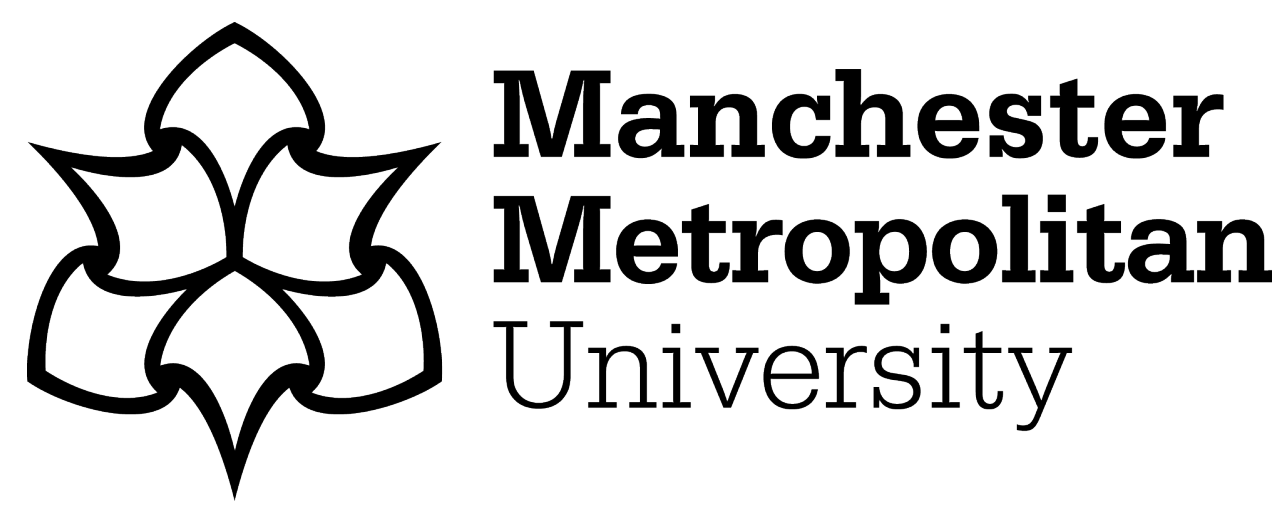

McVeigh, J ORCID logoORCID: https://orcid.org/0000-0001-5319-6885 and Begley, EK (2016) Anabolic steroids in the UK: an increasing issue for public health. Drugs: Education, Prevention \& Policy, 24 (3). pp. 278-285. ISSN 0968-7637

Downloaded from: https://e-space.mmu.ac.uk/624832/

Version: Accepted Version

Publisher: Taylor \& Francis

DOI: https://doi.org/10.1080/09687637.2016.1245713

Please cite the published version 


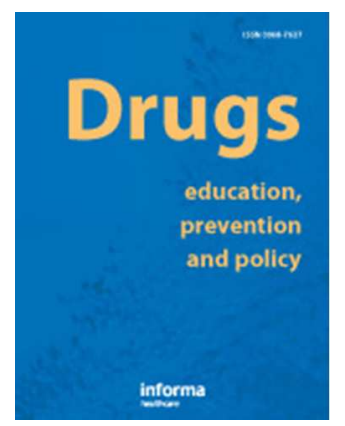

Anabolic steroids in the UK: an increasing issue for public health

\begin{tabular}{|r|l|}
\hline Journal: & Drugs: Education, Prevention \& Policy \\
\hline Manuscript ID & CDEP-2016-0106.R1 \\
\hline Manuscript Type: & Original papers \\
\hline Keywords: & $\begin{array}{l}\text { Anabolic Steroids, Needle and Syringe Programmes, HIV, Enhancement } \\
\text { Drugs }\end{array}$ \\
\hline \multicolumn{2}{|l}{} \\
\hline
\end{tabular}

SCHOLARONE ${ }^{m}$

Manuscripts 


\section{Anabolic Steroids in the UK: An increasing issue for Public Health}

Abbreviated title: Anabolic steroids in the UK 1995 \& 2015

Jim McVeigh \& Emma Begley

Public Health Institute, Liverpool John Moores University, Liverpool, United Kingdom

Correspondence: J. McVeigh, Public Health Institute, Liverpool John Moores University, Henry Cotton Campus, 15-21 Webster Street, Liverpool, UK. Telephone: 0151231 4512, email:

j.mcveigh@ljmu.ac.uk 


\title{
Anabolic Steroids in the UK: An increasing issue for Public Health
}

\begin{abstract}
Aims: The aim of the paper was to identify changes in the extent and patterns of anabolic steroid use in the United Kingdom to better understand the public health implications within the context of the current health-related evidence base.

Methods: Using the two time points of 1995 (prior to legislation changes in the United Kingdom) and 2015, a review of the evidence related to health harms was conducted, in conjunction with needle and syringe programme (NSP) data in Cheshire \& Merseyside (UK) relating to anabolic steroid users.

Findings: Dramatic increases in the numbers of anabolic steroid users accessing NSPs, 553 in 1995 to 2446 in 2015, now accounting for $54.9 \%$ of clients. With the inclusion of pharmacy NSPs, this rose to 5336 individual anabolic steroid users.

Conclusions: Key changes in our knowledge during the 20 years, in particular in relation to HIV prevalence, changes in the market and patterns of use make anabolic steroid use a public health concern. In the context of increasing numbers of injectors, there is a need for comprehensive interventions.
\end{abstract}

Key words: Anabolic Steroids, Needle and Syringe Programmes, HIV. 


\section{Anabolic Steroids in the UK: An increasing issue for Public Health}

\section{Introduction}

Whilst the media and much of society have focused on the use of drugs to enhance performance in elite sport, 'doping' or 'cheating', the reality is that the 21 st century has seen the use of anabolic steroids become commonplace within the general population of a number of countries, including the United Kingdom. The modern era of anabolic steroids commenced in the early part of the 20th Century. This was largely due to pharmacological developments, with the isolation of testosterone (de Kruif, 1945) and the rapid expansion of patent and secret remedies (British Medical Association, 1909). During the last twenty years, with advances in pharmacology, technology and the introduction and expansion of the Internet, there has been an unprecedented increase in interest, availability and use of enhancement drugs in general, and anabolic steroids in particular (Evans-Brown et al., 2012). The term anabolic steroids (sometimes termed anabolic androgenic steroids) relate to testosterone and its synthetic derivatives. Anabolic steroids are used illicitly for enhancing muscle growth and strength, boosting physical activity or sports performance, and for aesthetic purposes (Sagoe et al., 2014). There are few circumstances in which anabolic steroids are prescribed. Similarly, human growth hormone has limited medical uses (Evans-Brown \& McVeigh, 2009).

It is these muscular enhancement drugs, anabolic steroids and associated substances that this paper will examine, and take stock of the relative risks to the population. As our understanding of the actions of these drugs and the potential consequences of their selfdirected use has become more apparent over the last 20 years, we ask the question: 
'What are the public health implications of anabolic steroids and associated drugs in 2016?'

To assess the situation in the United Kingdom as it currently stands, comparisons between the situation in 1995 and 2016 will be made. With the major changes in anabolic steroid legislation occurring in 1996 (ACMD, 2010), it is an appropriate timeframe to examine. The paper will review the available evidence with relevance to the United Kingdom at these two points in time in relation to drug related harms and the practices employed by anabolic steroid users. This will be supplemented by data from needle and syringe programmes in the North West of England, for the year 1995 and 2015.

\section{Background}

\section{The mid 1990's}

Anabolic steroids have long been associated with a range of adverse effects, from the cosmetic and transient to the life-threatening (ACMD, 2010). However, much of the data relating to health harms are derived from case reports/series and cross-sectional studies that are observational in nature (Evans-Brown et al., 2009). This led Friedle (2000) to conclude that, based on the information available, (with the exception of orally active anabolic steroids) there was only limited evidence related to many of the potential adverse consequences of anabolic steroid use. This followed a detailed review of case reports of serious illness and death amongst athletes with associated anabolic steroid use. Between 1977 and 1995 relatively few cases were described, including several forms of cancer, myocardial infarctions and rare cases of HIV. Cerebrovascular thrombosis was singled out as a danger, with the 1980s and early 1990s also witnessing the emergence of cardiomyopathy secondary to 
anabolic steroids as a cause for concern (Ferenchick, 1996; McKillop et al., 1986). The safe use of testosterone as a male contraceptive provided a backdrop to this relative lack of concern (WHO, 1990).

At this time, the main threat appeared to be from the 17-alkylated anabolic steroids (these include oral anabolic steroids such as, methandienone and oxymetholone which are still in common usage today, Hope et al., 2013) with cases of acute liver toxicity resulting in serious damage. Cross-sectional data indicated impaired liver function in some users but it was not long before even this was questioned due to the difficulties in distinguishing between markers of hepatotoxicity and markers of muscle damage secondary to high-levels of resistance exercise (Dickerman et al., 1999).

Psychological harm and behaviour changes were cited as concerns at this time. Increasing evidence from the USA, in particular the work of Pope and colleagues (Pope, 1994; Pope \& Katz, 1992) illustrated the potential for psychological harms. Wide ranging effects (Parrott et al., 1994; Perry \& Hughes, 1992) including aggression (Su et al., 1993) and violence (Choi \& Pope, 1994; Malone et al. 1995; Pope \& Katz, 1990; Schulte et al., 1993) associated with the use of anabolic steroids were described in the literature. Interviews with anabolic steroid users in the United Kingdom in the mid-1990s revealed that 54\% had experienced feelings of aggression (Lenehan et al., 1996) supporting the earlier work by Korkia \& Stimson (1993), with findings not restricted to male users (Korkia et al., 1996).

Our understanding of the knowledge and practices of anabolic steroid users in the United Kingdom at that time largely stemmed from the work of Korkia and Stimson (1993), in which 110 steroid users were interviewed and the 386 interviews conducted in the North West of England by Lenehan et al,. (1996). While polypharmacy was common, it was usually restricted to a small number of anabolic steroids combined with drugs such as tamoxifen 
citrate and human chorionic gonadotrophin to combat unwanted side effects. The use of human growth hormone was rare amongst users of anabolic steroids, at $2.7 \%$ in the United Kingdom study (Korkia and Stimson, 1993) and 5.7\% in the North West of England study (Lenehan et al,. 1996).

The main source of information for users of anabolic steroids was the gym owner, followed by handbooks, (usually from the United States) with the Anabolic Reference Guide (Phillips, 1991) and the Underground Steroid Handbook II (Duchaine, 1989) being particularly popular. The central role of the gym owner was explored further with interviews conducted with 64 gym owners across the North West of England. Their main areas of concern related to the lack of reliable information on anabolic steroids and the amount of fake and counterfeit products on the market (McVeigh, 1996). The former is of interest as the subsequent expansion of the Internet would change beyond recognition, the amount of information available to anabolic steroid users, although not the central tenet of 'reliable information'. The latter is interesting as this was an area of concern that was only just emerging within the academic literature (McVeigh \& Lenehan, 1994; Musshoff et al., 1997; Perry, 1995; Walters et al., 1990). A third issue of concern raised by gym owners related to the use of anabolic steroids by young people. Over three-quarters of gym owners had observed increasing numbers of young males attending their gyms, ‘...using anabolic steroids without any understanding of potential harms' (McVeigh \& Lenehan, 1994).

It was this final issue, supported by data from studies in the United Kingdom (Williamson, 1993), Canada (Melia et al., 1996) and numerous studies from the United States (including Buckley, 1988; DuRant et al., 1995; Johnson et al., 1989) that influenced legislative changes, bringing anabolic steroids and associated drugs under the control of the Misuse of Drugs Act (1971) in the United Kingdom. 
On 1st September 1996, anabolic steroids and a number of associated drugs including growth hormones became controlled under the Misuse of Drugs Act (1971), following a recommendation from the Advisory Council for the Misuse of Drugs. Prior to the change in legislation, anabolic steroids came under the jurisdiction of the Medicines Control Agency, an arm of the Department of Health (ACMD, 2010). In April 2012, the phrase "medicinal product" was removed to reduce ambiguity and import restrictions placed on buying anabolic steroids and associated drugs from outside the United Kingdom. Anyone wishing to import these drugs from outside the United Kingdom is now required to do so in person (sometimes referred to as 'personal custody'). These changes were put in place in an attempt to curb the large anabolic steroid online market. Personal possession of these substances remains legal in the United Kingdom. However, Supply offences, including possession with intent to supply, carry a maximum sentence of 14 years and/or an unlimited fine (PHW, 2016).

\section{6}

While there remains significant gaps in our knowledge and understanding of anabolic steroids and associated drugs, many of the conditions that were considered to have the potential to cause adverse effects now have a much firmer evidence base. Much of this work has been conducted in North America, with contributions from Europe (in particular the Nordic countries) and Australia and are summarised in the Endocrine Society Scientific Statement (Pope et al., 2014). The statement highlights a number of adverse effects of anabolic steroids on various organs and systems of the body including hematologic effects, hepatic, musculoskeletal, renal, immunological and dermatological, together with hormonal and metabolic effects. Perhaps the greatest concern is reserved for the cardiovascular impact. Building on the extensive catalogue of cardiac damage (Angell et al., 2012), controlled studies have provided a greater understanding of potential harm to the heart such as 
hypertrophy and electrical instability (Baggish et al., 2010; Far et al., 2012; Krieg et al., 2007). Another area of increased understanding, relates to psychiatric, neuropsychologic and behavioural impact of anabolic steroids. The hypotheses of the mid 1990s have subsequently been supported in work within the general population and prison population (Klötz et al., 2010; Lundholm et al., 2010; Pope et al., 2000). There remains many unanswered questions relating to aggression and violence (Mazur, 2005) and the wider psychological effects of anabolic steroids including anxiety, depression and dependence. However, there is some consensus, that for many, anabolic steroids will have a relatively minor impact on behaviour and mental health, but for some the consequences can be severe (Pope et al., 2014). Even within the user population there are contradiction and ambivalence (Kimergard, 2015; Monaghan, 2001). It also appears that the anabolic steroid regimes employed (combinations and dosages), length of use, underlying psychological wellbeing and mental health, concomitant use of recreational psychoactive drugs may all pay a part in the extent of the adverse consequences of use.

There are several additional concerns, the extent of which had not been fully recognised 20 years ago. They are not pharmacological adverse effects and may even be considered as 'indirect effects', but from a public health perspective, have major implications. They relate to the drugs market and the method of administration respectively. The majority of available anabolic steroids are illicitly manufactured (ACMD, 2010; Evans-Brown et al., 2009; Evans-Brown et al., 2012; Graham et al., 2009; Kimergard et al., 2014a). This is not unique to the United Kingdom market (Cohen et al., 2007; Larance, 2005; Parkinson \& Evans, 2006; Striegel et al., 2006). Without the requisite quality assurance of legitimate manufacture, products are often contaminated with biological, chemical or foreign matter, variable in strength or substituted with different active ingredients. This has clear implications for health in relation to infection, over-dosage and unexpected adverse consequences (Thevis 
et al., 2008). This is not just an issue related to anabolic steroids but effects all illicitly manufactured image and performance enhancing drugs e.g. peptide hormones (Kimergard et al., 2014b), growth hormone releasing hormones (Stensballe et al., 2015), melanotan II (Breindahl et al., 2015), 2,4-Dinitrophenol (McVeigh et al., 2016) and even dietary supplements adulterated with anabolic steroids (Abbate et al., 2015) or ancillary drugs such as tamoxifen (Evans-Brown et al., 2014).

A further concern is how the substances are used. While polypharmacy has been the norm for in excess of 20 years in the United Kingdom (Korkia, 1993; Lenehan et al., 1996; McBride et al., 1996), there is unprecedented availability of a vast array of substances, some long established while others are still at the experimental stage (Chandler \& McVeigh, 2014; Hope et al., 2013; McVeigh et al., 2015). This is not unique to the United Kingdom but a global issue (Larance et al., 2008; Parkinson \& Evans, 2006; Sagoe et al., 2015; Skarberg et al., 2009). The most dramatic change in the use of drugs in conjunction with anabolic steroids, is the issue of human growth hormone. Similarly to the findings of Parkinson and Evans (2006), the United Kingdom, has experienced falling costs of producing and purchasing human growth hormone. In the 1990s growth hormone was purchased at between $£ 6.58-£ 20$ per IU (International Unit). By 2008 , the price had fallen to $£ 1.00-£ 8.33$ per IU (Evans-Brown \& McVeigh, 2009). This has resulted in 32\% of current anabolic steroid users having used human growth hormone in the previous year (Hope et al., 2013).

In addition to these changes in relation to anabolic steroids in the United Kingdom, a significant public health issue has emerged. Until recently, HIV and other blood borne virus prevalence and transmission was largely dismissed as a marginal public health concern. Case reports of HIV amongst users of anabolic steroids have been rare (Henrion et al., 1992; Scott \& Scott, 1989; Sklarek et al., 1984), surveillance of injecting drug users has failed to detect 
HIV amongst this population (Crampin et al., 1998) and the identification of the sharing of injecting equipment less common than amongst those who inject psychoactive drugs both in the United Kingdom (Midgley et al., 2000) and Australia (Iversen et al., 2013; Larance et al., 2008).

In 2013, the largest study of blood borne viruses in users of anabolic steroids and associated drugs was published. Samples from 395 men revealed that $1.5 \%$ had HIV, 9\% had antibodies to the hepatitis $\mathrm{B}$ core antigen (anti-HBc) and 5\% to hepatitis $\mathrm{C}$ (anti-HCV) (Hope et al., 2013). Furthermore, 36\% reported having redness, swelling and tenderness in the preceding year, and $6.8 \%$ had experienced an abscess or open wound at an injection site at some point in the past (Hope et al., 2015). Data from a subsequent survey (2012-2013), together with historical data were analysed, demonstrating that the blood borne virus prevalence among this population of injectors has increased, and levels of HIV are now similar to that amongst psychoactive drug injectors (Hope et al., 2016).

It is within this context of increasing public health concern regarding the use of anabolic steroids and associated drugs that the needle and syringe programme (NSP) monitoring system data at Liverpool John Moores University was interrogated to identify the extent of anabolic steroid use within the North West of England.

\section{Methods}

The NSP monitoring data from the years 1995 and 2015 were extracted to provide an indication of the number of anabolic steroid injectors accessing these services. There has been significant changes to the NSP surveillance system during the period between 1995 and 2015, however the monitoring principles remain the same. The earlier datasets were collected in paper format and manually entered onto a database, technological advances allowed for the 
latter datasets to be reported directly onto the Integrated Monitoring System (IMS) via online submissions or shared from services' own data collection systems. The system enables each transaction to be attributed to a specific individual. The client provides an attributor code (entailing initials, date of birth and sex), together with data relating to the drugs of injection enabling all subsequent visits and details of transaction to be recorded and attributed. The use of an attributor code such as this is now widely used within monitoring and surveillance systems in relation to substance use (for details on the Integrated Monitoring System see Whitfield et al., 2015). Data for all agency NSPs across Cheshire and Merseyside were analysed using SPSS v22 for the years 1995 and 2015 respectively. Figures were aggregated to Local Authority level (Cheshire, Halton, Knowsley, Liverpool, Sefton, St Helens, Warrington and the Wirral) and then further aggregated to provide totals for Cheshire and Merseyside as a whole. Client records were omitted if client's date of birth was less than 10 years of age.

Population data were derived from mid-1996 and mid-2014 with the age category 2029 used to calculate prevalence of steroid using NSP clients per 1,000 population. For 2015, an additional measure of 'all sources' was calculated. Not available in 1995, these figures relate to the total number of individual anabolic steroid users attending either agency NSP or pharmacy NSP. Further aggregation is included to remove duplicates across the two data sources. Table 2 relates to individual steroid using clients including the total number of syringes provided to each individual user.

\section{Results}

[Table 1 near here]

Cheshire and Merseyside, with a total population of 2,430,284 (ONS, 2016) was served by 18 
agency NSPs in 2015, and 17 agency NSPs in 1995. A total of 2,446 individual steroid users accessed agency needle and syringe programmes across Cheshire and Merseyside in 2015 compared with 553 in 1995, representing a 342\% increase over the period. Changes were not uniform across the geography, with dramatic increases in the Local Authorities in the County of Cheshire, Halton (HAL) (2,633\%), Cheshire (1,321\%) and Warrington (WAR) (703\%). In the more urbanised County of Merseyside, increase was pronounced but more modest, with the central Local Authority of Liverpool (LIV), reporting a decrease of $31 \%$.

Data indicate that anabolic steroid use is most common in the male age group of 20 to 29. This has been calculated for both years, indicating an increase from 1.88 per 1,000 population to 5.72 per 1,000 population. There exists a wide variation in the number of steroid users accessing NSPs per 1,000 population in the Local Authorities, rising as high as 16.78 in St Helens (SHL) and 18.76 in Halton (HAL).

All steroid users (all sources) incorporates data from the agency NSP and Pharmacy NSP and is only available for $2014 / 15$. The pharmacy data were obtained from 84 shops across Cheshire and Merseyside. Direct comparison of the total of number of anabolic steroid users in $2015(5,336)$ cannot be made with the agency only data of $1995(553)$. However, contemporary data from the mid-1990s indicates that the vast majority of injecting equipment provided from these outlets were suitable for intravenous injection only and would not be suitable for intramuscular anabolic steroid injection (Birtles \& Bellis, 1997), therefore enabling some level of comparison. This would indicate an even more dramatic increase in NSP provision for anabolic steroid users. While most Local Authorities experienced an increase in anabolic steroid user totals with the inclusion of the additional data source, the most dramatic increase occurred in Cheshire.

[Table 2 near here] 
The majority of agency NSP clients in Cheshire and Merseyside are injectors of anabolic steroids and associated drugs. During the last 20 years, the percentage of steroid users has risen from $17.1 \%$ to $54.9 \%$ and with males now accounting for $98.6 \%$ of all steroid using clients compared to $96.5 \%$ in 1995 . The mean age of steroid using clients also increased from 26 years old (median age of 25) in 1995 compared to 31 years old (median age of 30) in 2015. The total number of syringes dispensed rose from 14,293 to 139,956 , an increase of $879 \%$. This is not just as a result of an increased number of steroid users accessing NSPs but equates to more than a doubling of equipment per client.

\section{Discussion}

The last 20 years has witnessed significant changes in relation to substance use in general, not least in relation to the use of human enhancement drugs (Evans-Brown et al., 2012). Nowhere is this more pronounced than in the use of anabolic steroids and associated drugs, the number and diversity of drugs being used (Sagoe et al., 2015), the accompanying psychoactive drug use (Hope et al., 2013) and the massive dosages being used by even the most novice of users (Chandler \& McVeigh, 2014).

Increased research and opportunities to publish have seen an unprecedented amount of peer reviewed papers published on anabolic steroid use. In a basic search of academic papers using CINAHL, PsychINFO, Social Sciences Citations Index and Medline for relevant papers on the use of anabolic steroids and associated drugs, 95 unique references were generated for 1995 compared with 397 for 2015 . While this is partly as a result of the expansion of the Internet, still the majority of steroid users access their information from non-academic sources on the Web (Kimergard \& McVeigh, 2014c). The academic literature has provided a greatly improved understanding of the potential adverse effects of anabolic steroids and a range of 
associated drugs (Pope et al, 2014) and this will continue to improve as anabolic steroid users mature and the longer term impact of high levels of sustained drug use can be ascertained. The above issues are compounded by the fact that the vast majority of available products are manufactured illicitly or without due oversight in relation to 'quality, safety and efficacy' (MHRA, 2007) undermining the further development of the evidence base and basic harm reduction messages related to the specific substances and dosages (Evans-Brown et al., 2009).

The identification of HIV within this population is a significant concern. While we are unable to identify if the transmission is due to the sharing of anabolic steroid injecting equipment, sharing of equipment linked with previous (or current) psychoactive drug injection, sexual transmission or a combination of all these routes, the fact that it is established within the population, at the same level of that seen in psychoactive drug injectors has profound public health implications (Hope et al., 2013; Hope et al., 2015).

Clearly, to ascertain the extent of a potential public health issue, an estimate of the prevalence or at least an indication of the scale of the particular activity is required. We have some indication of prevalence of anabolic steroid use, Sagoe et al, estimated that the global lifetime prevalence for anabolic steroids is 3.3\% with higher levels across Europe (Sagoe et al, 2014). The Crime Survey for England and Wales (2014/15) suggests much lower levels of $0.9 \%$, although a statistically significant rise over the previous decade, with approximately 73,000 having used in the previous year (ONS, 2015). The Crime Survey for England and Wales is generally accepted to be a considerable underestimation of anabolic steroid use (ACMD, 2010; Bates et al., 2014). Previously published work has provided an indication as to the extent of anabolic steroid users at NSPs, in the geography examined here (McVeigh et al, 2003a; ACMD, 2010) and across the wider United Kingdom (Kimergard \& McVeigh, 2014c). This is however, the first time that a comparison over a prolonged period has taken place. The 
data illustrate a startling increase in the number of anabolic steroid users accessing NSPs. This cannot be used as a true proxy for changes in the prevalence of anabolic steroid use, as it may reflect an increased proportion of anabolic steroid users presenting to these services. This may be at least partially countered by the increased number of syringes being dispensed. It is long established that many steroid users in the United Kingdom will be provided with injecting equipment for other users of anabolic steroids (Korkia \& Stimson, 1993, Lenehan et al., 1996; Cullen et al, 2015) with this practice recognised by National Institute for Health \& Care Excellence (NICE, 2014) and mirrored in Australia (Dunn et al., 2014). While there have been changes over time in relation to the number and frequency of injections, we suggest that the 139,956 syringes provided by agency NSPs alone (this does not include the equipment dispensed from pharmacy NSPs or purchased online) is an indication of a large and growing population of anabolic steroid users.

It is of interest to consider the different patterns of change across the Local Authorities. Increases are by no means uniform, with stark contrast between the urban area of Liverpool to the more rural and affluent Cheshire. The inclusion of pharmacy data confirms that the different situation in Liverpool is not masked by a migration from one type of NSP to another. We hypothesise that this may at least partly be explained by a diffusion of high levels of anabolic steroid use from the central Liverpool area in the mid-1990s to the outer areas of Cheshire and Merseyside over the last 20 years.

While the origins of the diffusion theory can be traced back to the early 1900s (De Tarde, 1903), it is Rogers' Diffusion of Innovation (1983) and its application to drug use behaviour (Rogers, 1995) that support this explanation. Golub et al. (2005) describe a complex interaction of culture and individualism with drug use being an active decision where the 'setting' (Zinberg, 1984) is the main influence. The 'trickle down' effect of 
innovators and early adopters may explain the later adoption of high levels of anabolic steroid use occurring in the central urban section of the geographical area, spreading to the suburban/rural areas over time. This has similarities to previous phenomena that took place in Cheshire and Merseyside during the 1980s in relation to heroin use and the 1990s, in which the adoption of crack cocaine could be traced as emanating in Central Liverpool before expanding its reach across the region (McVeigh et al., 2003b).

There is a lack of evidence based interventions in relation to anabolic steroids. Currently, there are no formal academic evaluations of harm reduction, treatment or prevention interventions in the United Kingdom. Furthermore, there is scant evidence internationally (Backhouse et al., 2014). While prevention programmes such as 'Hercules' appear promising (implementation of a theoretical learning base and practical strength training sessions, Sagoe et al, 2016) in relation to positive changes in knowledge, similarly to other programmes, we do not have evidence of longer term positive behaviour change (Elliot et al., 2008; Fritz et al., 2005; Goldberg et al., 2007; Jalilian et al., 2011; Nilsson et al., 2004). With evidence of a range of serious health harms, not least the identification of HIV within the population, and indications of increasing prevalence, public health cannot wait for effective prevention interventions to be established and the need for a comprehensive harm reduction approach is required. Whilst the data here show an increasing number of anabolic steroid injectors attending needle and syringe programmes, it is recognised that this represents only a subset of this population and greater engagement efforts need to be made through outreach to gyms and other environments where anabolic steroid use is likely to be found (such as the night-time environment and occupations where size, strength or appearance are highly valued). 


\section{Conclusion}

Clearly, there have been significant changes in our understanding of anabolic steroid use together with the extent and practices of the users themselves. The recent identification of HIV within the population, the quality and safety of the illicit products being used, together with the established physical and psychological harms are causes for concern. The NSP surveillance system in Cheshire \& Merseyside provides evidence for the extent of anabolic steroid use, a phenomenon that is believed to be replicated across the United Kingdom and beyond. Detailed work is required relating to the causes and drivers of this situation, the risk behaviours of the individuals, the nature of the illicit market and role of the Internet together with the development of (cost) effective demand and harm reduction.

\section{Limitations}

The paper is set within a United Kingdom context and while some themes will be transferrable to other countries, the specifics related to legislation, service provision and to some extent cultural background, limits the extent to which it is generalizable. Furthermore the extent to which Cheshire and Merseyside is representative of the United Kingdom as a whole remains unknown, therefore there is a clear need for further research and surveillance within this particular population across wider geographies and over time. The literature reviews relating to the mid-1990s and 2015 are not systematic with potential bias towards work by the authors due to the nature and geography of their work. The data relating to the attendance at needle and syringe programmes is self-reported surveillance in nature with some differences in data collection methods (paper compared to electronic). We have no reason to believe that this would in any way skew the findings. 
Acknowledgments and conflict of interest

Staff at the Public Health Institute, LJMU, in particular Mark Whitfield and Howard Reed for preparation of needle and syringe data for 2015, Geoff Bates for literature retrieval and Jen Lovelady for proof reading the final manuscript. We would also like to thank contributing agencies to the NSP monitoring systems in Cheshire and Merseyside. The authors do not have any conflict of interest to declare. 
References

Abbate, V., Kicman, A. T., Evans-Brown, M., McVeigh, J., Cowan, D. A., Wilson, C., et al. (2015). Anabolic steroids detected in bodybuilding dietary supplements - a significant risk to public health. Drug Testing and Analysis, 7(7), 609-618.

ACMD. 2010. Advisory Council on the Misuse of Drugs, Consideration of the Anabolic Steroids, Home Office: London, 2010.

Angell, P. J., Chester, N., Sculthorpe, N., Whyte, G., George, K., \& Somauroo, J. (2012). Performance enhancing drug abuse and cardiovascular risk in athletes: implications for the clinician. British Journal of Sports Medicine, 46, 78-84.

British Medical Association. (1909). Secret remedies: what they cost and what they contain: British Medical Association.

Backhouse, S., Collins, C., Defoort, Y., McNamee, M., Parkinson, A., \& Sauer, M. (2014). Study on Doping Prevention: A map of Legal, Regulatory and Prevention Practice Provisions in EU 28. Luxembourg: Publications Office of the European Union.

Baggish, A. L., Weiner, R. B., Kanayama, G., Hudson, J. I., Picard, M. H., Hutter, A. M., \& Pope, H. (2010). Long-Term Anabolic-Androgenic Steroid Use Is Associated With Left Ventricular Dysfunction. Circulation-Heart Failure, 3(4), 472-U415.

Bates, G., Jones, L., \& McVeigh, J. (2014) Update of NICE Guidance PH18 Needle and Syringe Programmes (PIED Review). Centre for Public Health, Liverpool John Moores University.

Birtles, R., \& Bellis, M. (1997). Drug services in Merseyside and Cheshire 1996: prevalence and outcomes. Public Health Sector, Liverpool John Moores University.

Breindahl, T., Evans-Brown, M., Hindersson, P., McVeigh, J., Bellis, M., Stensballe, A., et al. (2015). Identification and characterization by LC-UV-MS/MS of melanotan II skin-tanning products sold illegally on the Internet. Drug Testing and Analysis, 7(2), 164-172.

Buckley, W. E. (1988). Estimated Prevalence of Anabolic Steroid Use Among Male High School Seniors. JAMA, 260(23), 3441.

Chandler, M., \& McVeigh, J. (2014). Steroids and image enhancing drugs 2013 survey results. Centre for Public Health, Liverpool John Moores University.

Choi, P. Y., \& Pope, H. G., Jr. (1994). Violence toward women and illicit androgenic-anabolic steroid use. Ann Clin Psychiatry, 6(1), 21-25.

Cohen, J., Collins, R., Darkes, J., \& Gwartney, D. (2007). A league of their own: demographics, motivations and patterns of use of 1,955 male adult non-medical anabolic steroid users in the United States. Journal of the International Society of Sports Nutrition, 4 (12). 
Crampin, A. C., Lamagni, T. L., Hope, V. D., Newham, J. A., Lewis, K. M., Parry, J. V., et al. (1998). The risk of infection with HIV and hepatitis B in individuals who inject steroids in England and Wales. Epidemiology and Infection, 121(2), 381-386.

Cullen, K.J., Hope, V., Parry, J. \& Ncube, F. (2015). Risk and vulnerability among people who inject image and performance enhancing drugs in England and Wales 2012-2013: Where should we focus harm reduction? In paper presented at the $24^{\text {th }}$ International Harm Reduction Conference, Kuala Lumpur, Malaysia. 2015.

de Kruif, P. (1945). The Male Hormone. London: Harcourt: Brace and Company.

De Tarde, G. (1903). The laws of imitation. New York: H. Holt and Co.

Dickerman, R. D., Pertusi, R. M., Zachariah, N. Y., Dufour, D. R., \& McConathy, W. J. (1999). Anabolic steroid-induced hepatotoxicity: Is it overstated? Clinical Journal of Sport Medicine, 9(1), 3439.

Duchaine, D. (1989). Underground steroid handbook II. Venice (CA): HLR Technical Books.

Dunn, M., McKay, F. H., \& Iversen, J. (2014). Steroid users and the unique challenge they pose to needle and syringe program workers. Drug and Alcohol Review, 33(1), 71-77.

DuRant, R. H., Escobedo, L. G., \& Heath, G. W. (1995). Anabolic-Steroid Use, Strength Training, and Multiple-Drug Use among Adolescents in the United-States. Pediatrics, 96(1), 23-28.

Golub, A., Johnson, B. D., \& Dunlap, E. (2005). Subcultural evolution and illicit drug use. Addiction Research \& Theory, 13(3), 217-229.

Elliot, D. L., Goldberg, L., Moe, E. L., Defrancesco, C. A., Durham, M. B., McGinnis, W., et al. (2008). Long-term Outcomes of the ATHENA (Athletes Targeting Healthy Exercise \& Nutrition Alternatives) Program for Female High School Athletes. J Alcohol Drug Educ, 52(2), 73-92.

Evans-Brown, M., Kimergard, A., \& McVeigh, J. (2009). Elephant in the room? The methodological implications for public health research of performance-enhancing drugs derived from the illicit market. Drug Testing and Analysis, 1(7-8), 323-326.

Evans-Brown, M., Kimergard, A., McVeigh, J., Chandler, M., \& Brandt, S. D. (2014). Bodybuilding Supplements; is the breast cancer drug tamoxifen being sold as a bodybuilding dietary supplement? British Medical Journal, 348.

Evans-Brown, M., \& McVeigh, J. (2009). Injecting human growth hormone as a performanceenhancing drug-perspectives from the United Kingdom. Journal of Substance Use, 14(5), 267288.

Evans-Brown, M., McVeigh, J., Perkins, C., \& Bellis, M. (2012). Human enhancement drugs: the emerging challenges to public health. Liverpool: North West Public Health Observatory. 
Far, H. R. M., Agren, G., \& Thiblin, I. (2012). Cardiac hypertrophy in deceased users of anabolic androgenic steroids: an investigation of autopsy findings. Cardiovascular Pathology, 21(4), 312-316.

Ferenchick, G. S. (1996). Validity of self-report in identifying anabolic steroid use among weightlifters. J Gen Intern Med, 11(9), 554-556.

Friedle, K. E. (2000). Effects of anabolic steroids on physical health Anabolic steroids in sport and exercise. Human Kinetics Publishers.

Fritz, M. S., MacKinnon, D. P., Williams, J., Goldberg, L., Moe, E. L., \& Elliot, D. L. (2005). Analysis of baseline by treatment interactions in a drug prevention and health promotion program for high school male athletes. Addictive Behaviors, 30(5), 1001-1005.

Goldberg, L., Elliot, D. L., MacKinnon, D. P., Moe, E. L., Kuehl, K. S., Yoon, M., et al. (2007). Outcomes of a prospective trial of student-athlete drug testing: The student athlete testing using random notification (SATURN) study. Journal of Adolescent Health, 41(5), 421-429.

Graham, M. R., Ryan, P., Baker, J. S., Davies, B., Thomas, N.-E., Cooper, S.-M., et al. (2009). Counterfeiting in performance-and image-enhancing drugs. Drug testing and analysis, 1(3), 135.

Henrion, R., Mandelbrot, L., \& Delfieu, D. (1992). Contamination par le VIH a la suite d'injections d'anabolisants. La presse medicale, 21(5).

Hope, V. D., Harris, R., McVeigh, J., Cullen, K. J., Smith, J., Parry, J. V., et al. (2016). Risk of HIV and Hepatitis B and C Over Time Among Men Who Inject Image and Performance Enhancing Drugs in England and Wales: Results From Cross-Sectional Prevalence Surveys, 1992-2013. JAIDS-Journal of Acquired Immune Deficiency Syndromes, 71(3), 331-337.

Hope, V. D., McVeigh, J., Marongiu, A., Evans-Brown, M., Smith, J., Kimergard, A., Croxford, S., Beynon, C.M., Parry, J.V., Bellis, M.A., \& Ncube, F. (2013). Prevalence of, and risk factors for, HIV, hepatitis B and C infections among men who inject image and performance enhancing drugs: a cross-sectional study. British Medical Journal, 3(9).

Hope, V. D., McVeigh, J., Marongiu, A., Evans-Brown, M., Smith, J., Kimergard, A., Parry, J.V. \& Ncube, F. (2015). Injection site infections and injuries in men who inject image- and performanceenhancing drugs: prevalence, risks factors, and healthcare seeking. Epidemiology and Infection, 143(1), 132-140.

Iversen, J., Topp, L., Wand, H., \& Maher, L. (2013). Are people who inject performance and imageenhancing drugs an increasing population of Needle and Syringe Program attendees? Drug and Alcohol Review, 32(2), 205-207. 
Jalilian, F., Allahverdipour, H., Moeini, B., \& Moghimbeigi, A. (2011). Effectiveness of Anabolic Steroid Preventative Intervention among Gym Users: Applying Theory of Planned Behavior. Health Promot Perspect, 1(1), 32-40.

Johnson, M. D., Jay, M. S., Shoup, B., \& Rickert, V. I. (1989). Anabolic-Steroid Use by MaleAdolescents. Pediatrics, 83(6), 921-924.

Kimergard, A. (2015). A qualitative study of anabolic steroid use amongst gym users in the United Kingdom: motives, beliefs and experiences. Journal of Substance Use, 20(4), 288-294.

Kimergard, A., Breindahl, T., Hindersson, P., \& McVeigh, J. (2014a). The composition of anabolic steroids from the illicit market is largely unknown: implications for clinical case reports. Qjman International Journal of Medicine, 107(7), 597-598.

Kimergard, A., \& McVeigh, J. (2014c). Variability and dilemmas in harm reduction for anabolic steroid users in the UK: a multi-area interview study. Harm Reduction Journal, 11:19.

Kimergard, A., McVeigh, J., Knutsson, S., Breindahl, T., \& Stensballe, A. (2014b). Online marketing of synthetic peptide hormones: poor manufacturing, user safety, and challenges to public health. Drug Testing and Analysis, 6(4), 396-398.

Klötz, F., Petersson, A., Hoffman, O., \& Thiblin, I. (2010). The significance of anabolic androgenic steroids in a Swedish prison population. Comprehensive Psychiatry, 51(3), 312-318.

Korkia, P., Lenehan. P., \& McVeigh, J. (1996). Non-medical use of androgens among women. Journal of Performance Enhancing Drugs, 1(2), 71.

Korkia, P., \& Stimson, G. V. (1993). Anabolic Steroid Use in Great Britain: An Exploratory Investigation : Final Report to the Departments of Health for England, Scotland and Wales. London: Centre for Research on Drugs Health Behaviour.

Krieg, A., Scharhag, J., Albers, T., Kindermann, W., \& Urhausen, A. (2007). Cardiac tissue Doppler in steroid users. International Journal of Sports Medicine, 28(8), 638-643.

Lenehan, P., Bellis, M., \& McVeigh, J. (1996). A study of anabolic steroid use in the North West of England. Journal of Performance Enhancing Drugs, 1(2).

Larance, B., Degenhardt, L., Copeland, J., \& Dillon, P. (2008). Injecting risk behaviour and related harm among men who use performance- and image-enhancing drugs. Drug and Alcohol Review, 27(6), 679-686.

Larance, B., Degenhardt, L., Dillon, P., \& Copeland, J. (2005). Rapid assessment of performance and image enhancing drugs (PIEDs) in New South Wales: Feasibility study (Vol. Technical Report No. 239): National Drug and Alcohol Research Centre.

Lundholm, L., Käll, K., Wallin, S., \& Thiblin, I. (2010). Use of anabolic androgenic steroids in substance abusers arrested for crime. Drug and Alcohol Dependence, 111(3), 222-226. 
Malone, D. A., Dimeff, R. J., Lombardo, J. A., \& Barry Sample, R. H. (1995). Psychiatric Effects and Psychoactive Substance Use in Anabolic-Androgenic Steroid Users. Clinical Journal of Sport Medicine, 5(1), 25-31.

Mazur, A. (2005). Biosociology of dominance and deference: Rowman \& Littlefield Publishers.

McBride, A. J., Williamson, K., \& Petersen, T. (1996). Three cases of nalbuphine hydrochloride dependence associated with anabolic steroid use. British Journal of Sports Medicine, 30(1), 69-70.

McKillop, G., Todd, I. C., \& Ballantyne, D. (1986). Increased left ventricular mass in a bodybuilder using anabolic steroids. British Journal of Sports Medicine, 20(4), 151-152.

McVeigh, J. (1996). Survey of gym owners' opinions on the use of performance enhancing drugs. Journal of Performance Enhancing Drugs, 1(1), 21.

McVeigh, J., Bates, G. \& Chandler, M. (2015). Steroids and Image Enhancing Drugs. Centre for Public Health: Liverpool John Moores University.

McVeigh, J., Beynon, C., \& Bellis, M. A. (2003a). New challenges for agency based syringe exchange schemes: analysis of 11 years of data (1991 to 2001) in Merseyside and Cheshire, UK. International Journal of Drug Policy, 399-405.

McVeigh, J., Germain, J., \& Van Hout, M. C. (2016). 2, 4-Dinitrophenol, the inferno drug: a netnographic study of user experiences in the quest for leanness. Journal of Substance Use, 1-8.

McVeigh, J., Hughes, K., Hounsome, J., \& Bellis, M. (2003b). Over a Decade of Drug Use Epidemiology. Center for Public Health, Liverpool John Moores University.

McVeigh, J., \& Lenehan, P. (1994). Counterfeits and fakes: a growing problem. Relay, 1(1), 8-9.

Melia, P., Pipe, A., \& Greenberg, L. (1996). The Use of Anabolic-Androgenic Steroids by Canadian Students. Clinical Journal of Sport Medicine, 6(1), 9-14.

MHRA. (2007). Medicines and Healthcare Products Regulatory Authority, Rules and Guidance for Pharmaceutical Manufacturers and Distributors 2007, Pharmaceutical Press: London, 2007, pp. 4-5.

Midgley, S. J., Heather, N., Best, D., Henderson, D., McCarthy, S., \& Davies, J. B. (2000). Risk behaviours for HIV and hepatitis infection among anabolic-androgenic steroid users. AIDS Care, 12(2), 163-170.

Monaghan, L. F. (2001). Bodybuilding, drugs, and risk. London ; New York: Routledge.

Musshoff, F., Daldrup, T., \& Ritsch, M. (1997). Black market in anabolic steroids - Analysis of illegally distributed products. Journal of Forensic Sciences, 42(6), 1119-1125. 
NICE. (2014). Needle and syringe programmes. Available at https://www.nice.org.uk/guidance/ph52/chapter/What-is-this-guidance-about (Accessed: 7 June 2016),

Nilsson, S., Allebeck, P., Marklund, B., Baigi, A., \& Fridlund, B. (2004). Evaluation of a health promotion programme to prevent the misuse of androgenic anabolic steroids among Swedish adolescents. Health Promotion International, 19(1), 61-67.

ONS. (2015). Drug Misuse: Findings from the 2014/15 Crime Survey for England and Wales. Home Office, Office for National Statistics.

ONS. (2016). Population estimates by single year of age and sex for local authorities in the UK, mid2014. Home Office, Office for National Statistics.

Parkinson, A. B., \& Evans, N. A. (2006). Anabolic androgenic steroids: A survey of 500 users. Medicine and Science in Sports and Exercise, 38(4), 644-651.

Parrott, A. C., Choi, P. Y. L., \& Davies, M. (1994). Anabolic-Steroid Use by Amateur Athletes - Effects Upon Psychological Mood States. Journal of Sports Medicine and Physical Fitness, 34(3), 292298.

Perry, H. (1995). Counterfeit-fake anabolic steroids and hazards of their use. Relay, 1(4), 9-12.

Perry, H., \& Hughes, G. (1992). A case of affective disorder associated with the misuse of'anabolic steroids'. British journal of sports medicine, 26(4), 219-220.

Phillips, W. N. (1991). Anabolic reference guide. Golden, CO, U.S.A.: Mile High Pub.

PHW. (2016). UK steroid law. Public Health Wales. Available at http://www.ipedinfo.co.uk/steroid_law.html (accessed: 6 June 2016).

Pope, H. G. (1994). Psychiatric and Medical Effects of Anabolic-Androgenic Steroid Use. Arch Gen Psychiatry, 51(5), 375.

Pope, H. G., \& Katz, D. L. (1990). Homicide and near-Homicide by Anabolic-Steroid Users. Journal of Clinical Psychiatry, 51(1), 28-31.

Pope, H. G., \& Katz, D. L. (1992). Psychiatric Effects of Anabolic-Steroids. Psychiatric Annals, 22(1), 2429.

Pope, H. G., Kouri, E. M., \& Hudson, J. I. (2000). Effects of supraphysiologic doses of testosterone on mood and aggression in normal men - A randomized controlled trial. Archives of General Psychiatry, 57(2), 133-140.

Pope, H. G., Wood, R. I., Rogol, A., Nyberg, F., Bowers, L., \& Bhasin, S. (2014). Adverse Health Consequences of Performance-Enhancing Drugs: An Endocrine Society Scientific Statement. Endocrine Reviews, 35(3), 341-375.

Rogers, E. M. (1983). Diffusion of innovations. (3rd ed). New York: The Free Press. 
Rogers, E. M. (1995). Diffusion of drug abuse prevention programs: spontaneous diffusion, agenda setting, and reinvention. In T. E. Backer, S. L. David \& G. P. Soucy (Eds.), Reviewing the behavioral science knowledge base on technology transfer (Vol. 155, pp. 90-105). Rockville, MD: United States Government Printing.

Sagoe, D., Holden, G., Rise, E. N. K., Torgersen, T., Paulsen, G., Krosshaug, T., et al. (2016). Doping prevention through anti-doping education and practical strength training: The Hercules program. Performance Enhancement \& Health.

Sagoe, D., McVeigh, J., Bjornebekk, A., Essilfie, M. S., Andreassen, C. S., \& Pallesen, S. (2015). Polypharmacy among anabolic-androgenic steroid users: a descriptive metasynthesis. Substance Abuse Treatment Prevention and Policy, 10:12.

Sagoe, D., Molde, H., Andreassen, C. S., Torsheim, T., \& Pallesen, S. (2014). The global epidemiology of anabolic-androgenic steroid use: a meta-analysis and meta-regression analysis. Annals of Epidemiology, 24(5), 383-398.

Schulte, H. M., Hall, M. J., \& Boyer, M. (1993). Domestic Violence Associated with Anabolic-Steroid Abuse. American Journal of Psychiatry, 150(2), 348-348.

Scott, M. J., \& Scott, M. J. (1989). Hiv Infection Associated with Injections of Anabolic-Steroids. JamaJournal of the American Medical Association, 262(2), 207-208.

Skarberg, K., Nyberg, F., \& Engstrom, I. (2009). Multisubstance Use as a Feature of Addiction to Anabolic-Androgenic Steroids. European Addiction Research, 15(2), 99-106.

Sklarek, H. M., Mantovani, R. P., Erens, E., Heisler, D., Niederman, M. S., \& Fein, A. M. (1984). Aids in a Bodybuilder Using Anabolic-Steroids. New England Journal of Medicine, 311(26), 17011701.

Stensballe, A., McVeigh, J., Breindahl, T., \& Kimergard, A. (2015). Synthetic growth hormone releasers detected in seized drugs: new trends in the use of drugs for performance enhancement. Addiction, 110(2), 368-369.

Striegel, H., Simon, P., Frisch, S., Roecker, K., Dietz, K., Dickhuth, H.-H., et al. (2006). Anabolic ergogenic substance users in fitness-sports: A distinct group supported by the health care system. Drug and Alcohol Dependence, 81(1), 11-19.

Su, T. P., Pagliaro, M., Schmidt, P. J., Pickar, D., Wolkowitz, O., \& Rubinow, D. R. (1993). Neuropsychiatric Effects of Anabolic-Steroids in Male Normal Volunteers. JAMA-Journal of the American Medical Association, 269(21), 2760-2764.

Thevis, M., Schrader, Y., Thomas, A., Sigmund, G., Geyer, H., \& Schanzer, W. (2008). Analysis of confiscated black market drugs using chromatographic and mass spectrometric approaches. Journal of Analytical Toxicology, 32(3), 232-240. 
Walters, M. J., Ayers, R. J., \& Brown, D. J. (1990). Analysis of Illegally Distributed Anabolic-Steroid Products by Liquid-Chromatography with Identity Confirmation by Mass-Spectrometry or Infrared Spectrophotometry. Journal of the Association of Official Analytical Chemists, 73(6), 904-926.

Whitfield M, R. H., Harrison, B., \& McVeigh, J. (2015). Integrated Monitoring System Report 2014/15. Centre for Public Health, Liverpool John Moores University.

WHO. (1990). Task Force on Methods for The Regulation of Male Fertility: Contraceptive efficacy of testosterone-induced azoospermia in normal men. The Lancet, 336(8721), 955-959.

Williamson, D. J. (1993). Anabolic steroid use among students at a British college of technology. British Journal of Sports Medicine, 27(3), 200-201.

Zinberg, N. E. (1984). Drug, set and setting. New Haven: Yale University. 
Table 1: Anabolic steroid users accessing needle and syringe programmes in Cheshire and Merseyside, United Kingdom during 1995 and 2015

\begin{tabular}{|c|c|c|c|c|c|c|c|c|c|}
\hline LA/DAT & $\begin{array}{c}1995 \text { No. of } \\
\text { steroid } \\
\text { users }\end{array}$ & $\begin{array}{c}2015 \text { No. of steroid } \\
\text { users } \\
\end{array}$ & \multicolumn{3}{|c|}{$\begin{array}{c}1995 \text { Male steroid users } \\
\text { aged } 20-29\end{array}$} & \multicolumn{3}{|c|}{$\begin{array}{c}2015 \text { Male steroid users } \\
\text { aged } 20-29\end{array}$} & $\begin{array}{c}2015 \\
\text { All steroid } \\
\text { users } \\
\text { (all sources) }\end{array}$ \\
\hline Cheshire & 29 & 412 & 17 & 42468 & 0.40 & 238 & 38083 & 6.25 & 1214 \\
\hline HAL & 12 & 328 & 10 & 8350 & 0.24 & 145 & 7731 & 18.76 & 616 \\
\hline KNW & 25 & 178 & 15 & 10119 & 1.48 & 79 & 9444 & 8.37 & 178 \\
\hline SHL & 45 & 411 & 33 & 12187 & 2.71 & 180 & 10729 & 16.78 & 605 \\
\hline WAR & 29 & 233 & 17 & 12908 & 1.32 & 122 & 12525 & 9.74 & 677 \\
\hline WIR & 150 & 646 & 96 & 18736 & 5.12 & 276 & 17697 & 15.60 & 980 \\
\hline
\end{tabular}


Table 2: Service uptake by anabolic steroid users accessing needle and syringe programmes in Cheshire and Merseyside, United Kingdom during 1995 and 2015

\begin{tabular}{lll}
\hline Variable & 1995 & $\mathbf{2 0 1 5}$ \\
\hline Proportion of total NSP clients & $17.1 \%$ & $54.9 \%$ \\
\hline Proportion male & $96.5 \%$ & $98.6 \%$ \\
\hline Sum of syringes & 14293 & 139956 \\
\hline No of syringes per individual & 26 & 57 \\
\hline Age of male NSP clients & & \\
\hline Mean & 26 & 31 \\
\hline Median & 25 & 30 \\
\hline
\end{tabular}

29

30

31

32 